\title{
Sensory intensity assessment of olive oils using an electronic tongue
}

\author{
Ana C.A. Veloso ${ }^{\mathrm{a}, \mathrm{b}}$, Luís G. Dias ${ }^{\mathrm{c}, \mathrm{d}}$, Nuno Rodrigues ${ }^{\mathrm{e}}$, José A. Pereira ${ }^{\mathrm{e}}$, António M. Peres ${ }^{\mathrm{f}, *}$ \\ a Instituto Politécnico de Coimbra, ISEC, DEQB, Rua Pedro Nunes, Quinta da Nora, 3030-199 Coimbra, Portugal \\ ${ }^{\mathrm{b}}$ CEB-Centre of Biological Engineering, University of Minho, Campus de Gualtar, 4710-057 Braga, Portugal

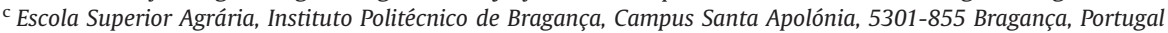 \\ d CQ-VR, Centro de Química - Vila Real, University of Trás-os-Montes e Alto Douro, Apartado 1013, 5001-801 Vila Real, Portugal \\ e CIMO-Mountain Research Centre, Escola Superior Agrária, Instituto Politécnico de Bragança, Campus Santa Apolónia, $5301-855$ Bragança, Portugal \\ ${ }^{\mathrm{f}}$ LSRE-Laboratory of Separation and Reaction Engineering-Associate Laboratory LSRE-LCM, Escola Superior Agrária, Instituto Politécnico de Bragança, \\ Campus Santa Apolónia, 5301-855 Bragança, Portugal
}

\section{A R T I C L E I N F O}

\section{Article history:}

Received 22 June 2015

Received in revised form 28 August 2015

Accepted 30 August 2015

Available online 1 September 2015

Keywords:

Single cultivar extra virgin olive oil

Sensory intensity perception classification

Potentiometric electronic tongue

Linear discriminant analysis

Simulated annealing algorithm

\begin{abstract}
A B S T R A C T
Olive oils may be commercialized as intense, medium or light, according to the intensity perception of fruitiness, bitterness and pungency attributes, assessed by a sensory panel. In this work, the capability of an electronic tongue to correctly classify olive oils according to the sensory intensity perception levels was evaluated. Cross-sensitivity and non-specific lipid polymeric membranes were used as sensors. The sensor device was firstly tested using quinine monohydrochloride standard solutions. Mean sensitivities of $14 \pm 2$ to $25 \pm 6 \mathrm{mV} /$ decade, depending on the type of plasticizer used in the lipid membranes, were obtained showing the device capability for evaluating bitterness. Then, linear discriminant models based on sub-sets of sensors, selected by a meta-heuristic simulated annealing algorithm, were established enabling to correctly classify $91 \%$ of olive oils according to their intensity sensory grade (leave-one-out cross-validation procedure). This capability was further evaluated using a repeated K-fold cross-validation procedure, showing that the electronic tongue allowed an average correct classification of $80 \%$ of the olive oils used for internal-validation. So, the electronic tongue can be seen as a taste sensor, allowing differentiating olive oils with different sensory intensities, and could be used as a preliminary, complementary and practical tool for panelists during olive oil sensory analysis.
\end{abstract}

(c) 2015 Elsevier B.V. All rights reserved.

\section{Introduction}

Different olive oils are commercially available and their prices depend on the olive oil quality grade (extra-virgin, EVOO; virgin or lampante), geographical origin and production procedure. Olive oils may also be labeled as intense, medium or light (mild), based on the sensory intensity perception of positive olfactory and gustatory-retronasal attributes. For this, olive oils fruitiness, bitterness and pungency levels are evaluated by trained sensory panelists, which besides being a time-consuming task, limits the maximum number of samples that may be assessed per day. Each attribute is evaluated using a quantitative scale (ranging from 0 (minimum) to 10 (maximum)), following the regulations of the International Olive Council [1,2].

Olive oils are highly appreciated by consumers and play a key role in several diets, due to the organoleptic attributes and the health benefits. The economic value of olive oils make this food product very prone to fraud, including mislabeling of olive oil

\footnotetext{
* Corresponding author. Fax: + 351273325405

E-mail address: peres@ipb.pt (A.M. Peres).
}

commercial category, geographical or olive cultivar origin [3-7]. So, several gas-, liquid- and mass-spectrometry chromatography, DNA and spectroscopy based methods have been developed to assess olive oil quality and authenticity as well as to detect possible adulterations [3,5,6,8-16]. Electrochemical sensors have also been extensively used, including electronic noses and electronic tongues (E-tongues), individually or in combination, mainly with the aim of identifying possible adulterations or classifying olive oils according to quality level, geographical origin or olive cultivar [16-28]. Recently, a "magnetic tongue" was used to quantify minor compounds of EVOO that are related to the sensory attributes [29]. However, the potential of electrochemical devices to classify olive oils based on the intensity perception of positive sensory attributes was never investigated. The availability of fast and cost-effective analytical techniques for preliminary verification of the compliance of this high quality EVOO qualitative classification (i.e., intense, medium or light olive oils) is a challenge task and pertinent issue since (i) nowadays, consumers increasingly require this kind of olive oil label information; (ii) olive oil producers are using this information as an additional organoleptic information in their products to increase its commercial value; and, (iii) the maximum number of olive oils that can be evaluated per day by a trained 
sensory panel is quite limited. So the capability of a potentiometric E-tongue to classify monovarietal EVOO according to the perceived sensory intensity level (i.e., light, medium or intense) was evaluated. Since olive oils are non-conductive and high viscous, the potentiometric signals were recorded in ethanol-water extracts, which are rich in polar compounds that are related with bitterness, pungency and astringency sensations. The olive oil samples analyzed were collected during two crop years (2012 and 2013) and belong to 11 Spanish single-cultivar EVOO: cvs. Arbequina, Arbosana, Arroniz, Cornicabra, Frantoio, Hojiblanca, Manzanilla, Picual, Redondilla, Royuela and Zorzal. The classification performance of the E-tongue was assessed using linear discriminant analysis (LDA) based on the most informative potentiometric sensor signals selected using a meta-heuristic simulated annealing (SA) algorithm.

\section{Materials and methods}

\subsection{Reagents}

In all assays, deionized type II water was used. Folin-Ciocalteau, sodium carbonate, n-hexane, methanol and ethanol were of analytical grade (Panreac, Barcelona). Quinine monohydrochloride dihydrate was purchased to Sigma-Aldrich (p.a., minimum purity $\geq 90 \%$ ). For E-tongue arrays construction, all reagents were from Fluka (minimum purity $\geq 97 \%$ ): plasticizers (bis(1-butylpentyl) adipate, dibutyl sebacate, 2-nitrophenyl-octylether, tris(2-ethylhexyl)phosphate and dioctyl phenylphosphonate) and additives (octadecylamine, oleyl alcohol, methyltrioctylammonium chloride and oleic acid). High molecular weight polyvinyl chloride was used as the supporting polymer (Fluka).

\subsection{Olive oil samples}

Eleven monovarietal Spanish EVOOs (cvs. Arbequina, Arbosana, Arroniz, Cornicabra, Frantoio, Hojiblanca, Manzanilla, Picual, Redondilla, Royuela and Zorzal), produced at the north of Spain (Valladolid region), were studied. In total, 88 different samples of single-cultivar EVOO were obtained directly from olive oil certified producers during 2012-2013 (Table 1). Olive oils were packed and stored in dark at $-20{ }^{\circ} \mathrm{C}$ in a 24 -h period after their production in olive mills with a two-phase extraction process and kept in those conditions until further analysis.

\subsection{Olive oil total phenolic content}

Total phenolic contents were determined as described by Capannesi et al. [30] with some modifications. A mass of $2.5 \mathrm{~g}$ of olive oil was diluted with n-hexane $(1: 1)$ and extracted three times with $2.5 \mathrm{~mL}$ of methanol/water $(80: 20 ; \mathrm{v} / \mathrm{v})$. The mixture was then centrifuged ( $5 \mathrm{~min}$ at $2600 \mathrm{~g}$ ). To $1 \mathrm{~mL}$ of the combined extract it was added $1 \mathrm{~mL}$ of Folin-Ciocalteau reagent, $1 \mathrm{~mL}$ of $\mathrm{Na}_{2} \mathrm{CO}_{3}$ solution (7.5\%) and $7 \mathrm{~mL}$ of deionized water, in order to obtain a final volume of $10 \mathrm{~mL}$. After homogenization, the mixture was stored overnight and spectrophotometrically analyzed $(\lambda=765 \mathrm{~nm})$. For quantification purposes a calibration curve between the measured absorbance and the concentration of caffeic acid in methanol was established (dynamic concentration range: $0.04-0.18 \mathrm{mg} / \mathrm{mL}$ ). A new calibration curve was established each day before olive oil analysis $\left(R^{2}\right.$-Pearson $\left.\geq 0.996\right)$. The final results were expressed as mg of caffeic acid equivalents per $\mathrm{kg}$ of olive oil (mg CAE $/ \mathrm{kg}$ ).

\subsection{Olive oil sensory analysis}

Olive oil samples were subjected to sensory assessment following the methods and standards adopted by the International Olive Council (COI), namely COI/T.20/Doc. no 15/Rev. 6 [1] and COI/ T.30/Doc. no 17 [2]. Each sample was subjected to the judgment of four trained panel members that classified the samples according to olfactory sensations, gustatory - retronasal sensations and final olfactory-gustatory sensations. Based on these evaluations and following the COI regulations, monovarietal EVOO samples were classified as intense, medium or light/mild olive oils according to the intensity perception of four positive attributes (olfactory and gustatory olive fruitiness; gustatory-retronasal bitterness and pungency). This labeling classification is based on the median

Table 1

Details of the monovarietal EVOO samples collected in Valladolid region (Spain): olive cultivar, production year, intensity perception level of positive sensory attributes.

\begin{tabular}{|c|c|c|c|c|c|c|c|}
\hline \multirow{3}{*}{$\begin{array}{l}\text { Monovarietal EVOO } \\
\text { Arbequina }\end{array}$} & \multirow{3}{*}{$\begin{array}{l}\text { Production year } \\
2012\end{array}$} & \multirow{3}{*}{$\begin{array}{l}\text { Number of samples } \\
2\end{array}$} & \multicolumn{4}{|c|}{$\begin{array}{l}\text { Intensity perception of positive sensory attributes (Intenational Olive Council, 2013) } \\
\text { Gustatory-retronasal sensations }\end{array}$} & \multirow[t]{2}{*}{ Group } \\
\hline & & & \multicolumn{2}{|c|}{ Olive fruitiness } & \multirow{2}{*}{$\begin{array}{l}\text { Bitterness } \\
\text { Intense }\end{array}$} & \multirow[t]{2}{*}{ Pungency } & \\
\hline & & & Intense & Intense & & & IIII \\
\hline & & 3 & Intense & Intense & Medium & Intense & IIMI \\
\hline & & 7 & Intense & Intense & Medium & Medium & IIMM \\
\hline & 2013 & 4 & Intense & Intense & Medium & Intense & IIMI \\
\hline & & 8 & Intense & Intense & Medium & Medium & IIMM \\
\hline \multirow[t]{2}{*}{ Arbosana } & 2012 & 4 & Intense & Intense & Intense & Intense & IIII \\
\hline & 2013 & 4 & Intense & Intense & Medium & Intense & IIMI \\
\hline Arroniz & 2012 & 4 & Intense & Intense & Medium & Intense & IIMI \\
\hline \multirow[t]{2}{*}{ Cornicabra } & 2012 & 4 & Intense & Intense & Medium & Intense & IIMI \\
\hline & 2013 & 4 & Intense & Intense & Medium & Medium & IIMM \\
\hline \multirow[t]{2}{*}{ Frantoio } & 2012 & 4 & Intense & Intense & Medium & Intense & IIMI \\
\hline & 2013 & 4 & Intense & Intense & Medium & Intense & IIMI \\
\hline \multirow[t]{2}{*}{ Hojiblanca } & 2012 & 4 & Intense & Intense & Intense & Intense & IIII \\
\hline & 2013 & 4 & Intense & Intense & Intense & Intense & IIII \\
\hline Manzanilla & 2012 & 4 & Intense & Intense & Light & Light & IILL \\
\hline \multirow{2}{*}{ Picual } & 2012 & 4 & Intense & Intense & Medium & Intense & IIMI \\
\hline & 2013 & 4 & Intense & Intense & Medium & Intense & IIMI \\
\hline \multirow[t]{2}{*}{ Redondilla } & 2012 & 4 & Intense & Intense & Medium & Medium & IIMM \\
\hline & 2013 & 4 & Intense & Intense & Medium & Medium & IIMM \\
\hline Royuela & 2013 & 4 & Intense & Intense & Intense & Intense & IIII \\
\hline Zorzal & 2013 & 4 & Intense & Intense & Medium & Intense & IIMI \\
\hline
\end{tabular}


Table 2

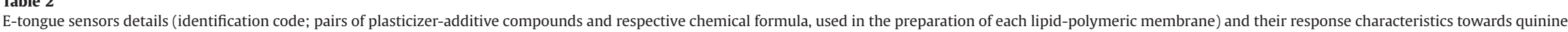
monohydrochloride (sensitivities and linear dynamic concentration ranges).

\begin{tabular}{|c|c|c|c|c|}
\hline $\begin{array}{l}\text { Sensor (or replica) ID } \\
\text { no. }^{\text {a }}\end{array}$ & Plasticizer compound $^{\mathrm{b}}(\approx 65 \%)$ (chemical formula) & Additive compound $^{\mathrm{C}}(\approx 3 \%)$ (chemical formula) & $\begin{array}{l}\text { Sensitivity }{ }^{\mathrm{d}} \overline{\boldsymbol{x}} \pm s, \mathrm{mV} / \\
\text { decade }\end{array}$ & Linear dynamic concentration range \\
\hline $\mathrm{S} 1: 1(\mathrm{~S} 2: 1)$ & Bis(1-butylpentyl) adipate $\left(\left[-\left(\mathrm{CH}_{2}\right)_{2} \mathrm{COOCH}\left[\left(\mathrm{CH}_{2}\right)_{3} \mathrm{CH}_{3}\right]_{2}\right]_{2}\right)$ & Octadecylamine; $\left(\mathrm{CH}_{3}\left(\mathrm{CH}_{2}\right)_{17} \mathrm{NH}_{2}\right)$ & $32 \pm 5$ & $\begin{array}{l}1.7 \times 10^{-5}-1.3 \times 10^{-4} \mathrm{M}(0.007-0.051 \mathrm{~g} / \\
\mathrm{L})\end{array}$ \\
\hline $\mathrm{S} 1: 2(\mathrm{~S} 2: 2)$ & & Oleyl alcohol; $\left(\mathrm{CH}_{3}\left(\mathrm{CH}_{2}\right)_{7} \mathrm{CH}=\mathrm{CH}\left(\mathrm{CH}_{2}\right)_{7} \mathrm{CH}_{2} \mathrm{OH}\right)$ & $23 \pm 4$ & $\begin{array}{l}7.4 \times 10^{-6}-1.8 \times 10^{-4} \mathrm{M}(0.003-0.070 \mathrm{~g} / \\
\mathrm{L})\end{array}$ \\
\hline $\mathrm{S} 1: 3(\mathrm{~S} 2: 3)$ & & Methyltrioctylammonium chloride; $\left(\left[\mathrm{CH}_{3}\left(\mathrm{CH}_{2}\right)_{6} \mathrm{CH}_{2}\right]_{3} \mathrm{~N}(\mathrm{Cl}) \mathrm{CH}_{3}\right)$ & $20 \pm 2$ & $\begin{array}{l}2.6 \times 10^{-6}-1.8 \times 10^{-4} \mathrm{M}(0.001- \\
0.070 \mathrm{~g} / \mathrm{L})\end{array}$ \\
\hline S1:4 (S2:4) & & Oleic acid; $\left(\mathrm{CH}_{3}\left(\mathrm{CH}_{2}\right)_{7} \mathrm{CH}=\mathrm{CH}\left(\mathrm{CH}_{2}\right)_{7} \mathrm{COOH}\right)$ & $23 \pm 5$ & $\begin{array}{l}1.7 \times 10^{-5}-1.3 \times 10^{-4} \mathrm{M}(0.007-0.051 \mathrm{~g} / \\
\mathrm{L})\end{array}$ \\
\hline S1:5 (S2:5) & Dibutyl sebacate; $\left(\left[-\left(\mathrm{CH}_{2}\right)_{4} \mathrm{CO}_{2}\left(\mathrm{CH}_{2}\right)_{3} \mathrm{CH}_{3}\right]\right)$ & Octadecylamine; $\left(\mathrm{CH}_{3}\left(\mathrm{CH}_{2}\right)_{17} \mathrm{NH}_{2}\right)$ & $24 \pm 4$ & $\begin{array}{l}7.4 \times 10^{-6}-2.2 \times 10^{-4} \mathrm{M}(0.003- \\
0.086 \mathrm{~g} / \mathrm{L})\end{array}$ \\
\hline S1:6 (S2:6) & & Oleyl alcohol; $\left(\mathrm{CH}_{3}\left(\mathrm{CH}_{2}\right)_{7} \mathrm{CH}=\mathrm{CH}\left(\mathrm{CH}_{2}\right)_{7} \mathrm{CH}_{2} \mathrm{OH}\right)$ & $27 \pm 7$ & $\begin{array}{l}1.7 \times 10^{-5}-1.3 \times 10^{-4} \mathrm{M}(0.007-0.051 \mathrm{~g} / \\
\mathrm{L})\end{array}$ \\
\hline S1:7 (S2:7) & & Methyltrioctylammonium chloride; $\left(\left[\mathrm{CH}_{3}\left(\mathrm{CH}_{2}\right)_{6} \mathrm{CH}_{2}\right]_{3} \mathrm{~N}(\mathrm{Cl}) \mathrm{CH}_{3}\right)$ & $20.5 \pm 0.4$ & $\begin{array}{l}7.4 \times 10^{-6}-1.3 \times 10^{-4} \mathrm{M}(0.003-0.051 \mathrm{~g} / \\
\mathrm{L})\end{array}$ \\
\hline $\mathrm{S} 1: 8(\mathrm{~S} 2: 8)$ & & Oleic acid; $\left(\mathrm{CH}_{3}\left(\mathrm{CH}_{2}\right)_{7} \mathrm{CH}=\mathrm{CH}\left(\mathrm{CH}_{2}\right)_{7} \mathrm{COOH}\right)$ & $23 \pm 9$ & $\begin{array}{l}7.4 \times 10^{-6}-9.4 \times 10^{-4} \mathrm{M}(0.001-0.051 \mathrm{~g} / \\
\mathrm{L})\end{array}$ \\
\hline S1:9 (S2:9) & 2-Nitrophenyl-octyl ether $\left(\mathrm{O}_{2} \mathrm{NC}_{6} \mathrm{H}_{4} \mathrm{O}\left(\mathrm{CH}_{2}\right)_{7} \mathrm{CH}_{3}\right)$ & Octadecylamine; $\left(\mathrm{CH}_{3}\left(\mathrm{CH}_{2}\right)_{17} \mathrm{NH}_{2}\right)$ & $18 \pm 8$ & $\begin{array}{l}3.3 \times 10^{-5}-1.3 \times 10^{-4} \mathrm{M}(0.013-0.051 \mathrm{~g} / \\
\mathrm{L})\end{array}$ \\
\hline S1:10 (S2:10) & & Oleyl alcohol; $\left(\mathrm{CH}_{3}\left(\mathrm{CH}_{2}\right)_{7} \mathrm{CH}=\mathrm{CH}\left(\mathrm{CH}_{2}\right)_{7} \mathrm{CH}_{2} \mathrm{OH}\right)$ & $19 \pm 3$ & $\begin{array}{l}2.6 \times 10^{-6}-2.2 \times 10^{-4} \mathrm{M}(0.001- \\
0.086 \mathrm{~g} / \mathrm{L})\end{array}$ \\
\hline S1:11 (S2:11) & & Methyltrioctylammonium chloride; $\left(\left[\mathrm{CH}_{3}\left(\mathrm{CH}_{2}\right)_{6} \mathrm{CH}_{2}\right]_{3} \mathrm{~N}(\mathrm{Cl}) \mathrm{CH}_{3}\right)$ & $12 \pm 1$ & $\begin{array}{l}2.6 \times 10^{-6}-2.5 \times 10^{-4} \mathrm{M}(0.001-0.101 \mathrm{~g} / \\
\mathrm{L})\end{array}$ \\
\hline $\mathrm{S} 1: 12(\mathrm{~S} 2: 12)$ & & Oleic acid; $\left(\mathrm{CH}_{3}\left(\mathrm{CH}_{2}\right)_{7} \mathrm{CH}=\mathrm{CH}\left(\mathrm{CH}_{2}\right)_{7} \mathrm{COOH}\right)$ & $17 \pm 4$ & $\begin{array}{l}7.4 \times 10^{-6}-2.5 \times 10^{-4} \mathrm{M}(0.003-0.101 \mathrm{~g} / \\
\mathrm{L})\end{array}$ \\
\hline S1:13 (S2:13) & Tris(2-ethylhexyl) phosphate $\left(\left[\mathrm{CH}_{3}\left(\mathrm{CH}_{2}\right)_{3} \mathrm{CH}\left(\mathrm{C}_{2} \mathrm{H}_{5}\right) \mathrm{CH}_{2} \mathrm{O}\right]_{3} \mathrm{P}(\mathrm{O})\right)$ & Octadecylamine; $\left(\mathrm{CH}_{3}\left(\mathrm{CH}_{2}\right)_{17} \mathrm{NH}_{2}\right)$ & $14 \pm 2$ & $\begin{array}{l}2.6 \times 10^{-6}-2.5 \times 10^{-4} \mathrm{M}(0.001-0.101 \mathrm{~g} / \\
\mathrm{L})\end{array}$ \\
\hline S1:14 (S2:14) & & Oleyl alcohol; $\left(\mathrm{CH}_{3}\left(\mathrm{CH}_{2}\right)_{7} \mathrm{CH}=\mathrm{CH}\left(\mathrm{CH}_{2}\right)_{7} \mathrm{CH}_{2} \mathrm{OH}\right)$ & $13 \pm 3$ & $\begin{array}{l}2.6 \times 10^{-6}-2.5 \times 10^{-4} \mathrm{M}(0.001-0.101 \mathrm{~g} / \\
\mathrm{L})\end{array}$ \\
\hline S1:15 (S2:15) & & Methyltrioctylammonium chloride; $\left(\left[\mathrm{CH}_{3}\left(\mathrm{CH}_{2}\right)_{6} \mathrm{CH}_{2}\right]_{3} \mathrm{~N}(\mathrm{Cl}) \mathrm{CH}_{3}\right)$ & $12.4 \pm 0.1$ & $\begin{array}{l}2.6 \times 10^{-6}-9.4 \times 10^{-4} \mathrm{M}(0.001- \\
0.037 \mathrm{~g} / \mathrm{L})\end{array}$ \\
\hline S1:16 (S2:16) & & Oleic acid; $\left(\mathrm{CH}_{3}\left(\mathrm{CH}_{2}\right)_{7} \mathrm{CH}=\mathrm{CH}\left(\mathrm{CH}_{2}\right)_{7} \mathrm{COOH}\right)$ & $16.1 \pm 0.3$ & $\begin{array}{l}2.6 \times 10^{-6}-2.5 \times 10^{-4} \mathrm{M}(0.001-0.101 \mathrm{~g} / \\
\mathrm{L})\end{array}$ \\
\hline S1:17 (S2:17) & Dioctyl phenylphosphonate $\left(\mathrm{C}_{6} \mathrm{H}_{5} \mathrm{P}(\mathrm{O})\left[\mathrm{O}\left(\mathrm{CH}_{2}\right)_{7} \mathrm{CH}_{3}\right]_{2}\right)$ & Octadecylamine; $\left(\mathrm{CH}_{3}\left(\mathrm{CH}_{2}\right)_{17} \mathrm{NH}_{2}\right)$ & $15 \pm 4$ & $\begin{array}{l}2.6 \times 10^{-6}-1.8 \times 10^{-4} \mathrm{M}(0.001- \\
0.070 \mathrm{~g} / \mathrm{L})\end{array}$ \\
\hline S1:18 (S2:18) & & Oleyl alcohol; $\left(\mathrm{CH}_{3}\left(\mathrm{CH}_{2}\right)_{7} \mathrm{CH}=\mathrm{CH}\left(\mathrm{CH}_{2}\right)_{7} \mathrm{CH}_{2} \mathrm{OH}\right)$ & $15.6 \pm 0.4$ & $\begin{array}{l}2.6 \times 10^{-6}-1.8 \times 10^{-4} \mathrm{M}(0.001- \\
0.070 \mathrm{~g} / \mathrm{L})\end{array}$ \\
\hline S1:19 (S2:19) & & Methyltrioctylammonium chloride; $\left(\left[\mathrm{CH}_{3}\left(\mathrm{CH}_{2}\right)_{6} \mathrm{CH}_{2}\right]_{3} \mathrm{~N}(\mathrm{Cl}) \mathrm{CH}_{3}\right)$ & $20 \pm 2$ & $\begin{array}{l}7.4 \times 10^{-6}-1.8 \times 10^{-4} \mathrm{M}(0.001-0.070 \mathrm{~g} / \\
\mathrm{L})\end{array}$ \\
\hline S1:20 (S2:20) & & Oleic acid; $\left(\mathrm{CH}_{3}\left(\mathrm{CH}_{2}\right)_{7} \mathrm{CH}=\mathrm{CH}\left(\mathrm{CH}_{2}\right)_{7} \mathrm{COOH}\right)$ & $19 \pm 3$ & $\begin{array}{l}1.7 \times 10^{-5}-2.5 \times 10^{-4} \mathrm{M}(0.007-0.101 \mathrm{~g} / \\
\mathrm{L})\end{array}$ \\
\hline
\end{tabular}

a Sensor identification number: $\mathrm{S}$ - sensor; number - code of the sensor array; 2nd number plasticizer-additive combination.

${ }^{\mathrm{b}}$ All plasticizers were selectophore ${ }^{\mathrm{TM}}$ grade from Fluka, with purity $\geq 97 \%$.

${ }^{c}$ All additives were from Fluka, with purity $\geq 97 \%$.

d : mean sensitivity value (mV/decade); : standard deviation of the sensitivities values ( $\mathrm{mV} /$ decade). 
value of the classification attributed by each panelist, in a $0-10$ scale (or reconverted to this scale) according to the International Olive Council [1]: (i) intense, when the median of the attribute is greater than 6; (ii) medium, when the median of the attribute is between 3 and 6; and (iii) light or mild, when the median of the attribute is less than 3 .

\subsection{E-tongue device}

The E-tongue included two print-screen potentiometric arrays containing 20 sensors (diameter: $3.6 \mathrm{~mm}$; thickness: $0.3 \mathrm{~mm}$ ) obtained from the combination of 4 different lipid additives (octadecylamine, oleyl alcohol, methyltrioctylammonium chloride and oleic acid; $\approx 3 \%$ ); 5 different plasticizers (bis(1-butylpentyl) adipate, dibutyl sebacate, 2-nitrophenyl-octylether, tris(2-ethylhexyl)phosphate and dioctyl phenylphosphonate; $\approx 65 \%$ ) and high molecular weight polyvinyl chloride (PVC; $\approx 32 \%$ ) (Table 2 ). The type of sensors and polymeric membrane compositions (relative percentage of additive, plasticizer and PVC) were selected based on a previous work [31] considering the satisfactory signal stability over time (\%RSD $<5 \%$, for $5 \mathrm{~min}$ signal record) and repeatability $(0.5 \%<\%$ RSD $<15 \%$, for three solutions with the same concentration at three levels ranging from $1 \times 10^{-5}$ to $1 \times 10^{-1} \mathrm{~mol} / \mathrm{L}$ ) towards the basic standard taste compounds (sweet, acid, bitter, salty and umami). Lipid polymeric membranes were used since they promote interactions with taste substances via electrostatic or hydrophobic interactions [32]. Each sensor is identified with a letter $S$ (for sensor) followed by a code for the sensor array (1: or 2:) and the number of the membrane (1 to 20 , corresponding to different combinations of plasticizer and additive used). Fig. 1 shows a scheme exemplifying the olive oil extracts analysis using the E-tongue and the potentiometric signal stability over time for one assay.

\subsection{E-tongue capability for perceiving bitterness intensity using} quinine standard solutions

To evaluate if the E-tongue could detect different intensities of positive sensory attributes, namely bitterness, preliminary assays were carried out using quinine monohydrochloride dihydrate standard solutions (ethanol-water, 80:20 v/v). Quinine was chosen since it is usually used as the reference standard for bitter sensation evaluation during sensory panel training. The E-tongue signal profiles were recorded for quinine standard solutions ranging from 0.001 to $0.1 \mathrm{~g} / \mathrm{L}$, in order to include quinine concentrations $(0.025-$ $0.050 \mathrm{~g} / \mathrm{L}$ ) described in the official procedure for training a sensory panel for EVOO evaluation $[33,34]$.

\subsection{Olive oil extraction procedure and E-tongue analysis}

Olive oils were extracted using ethanol-water solutions (80:20 $\mathrm{v} / \mathrm{v}$ ) and electrochemically analyzed as previously described [21]. Each olive oil was analyzed once. In all extractions, deionized water and ethanol (p.a.) were used. In each assay, $10.00 \mathrm{~g}$ of olive oil were mixed to $100 \mathrm{~mL}$ of hydro-ethanolic solution during 510 min under strong agitation. This process allowed extracting polar compounds, which are related to the bitterness, pungency and astringency sensations of olive oils. The mixture was left at ambient temperature during $60 \mathrm{~min}$, after which, $40.0 \mathrm{~mL}$ of the supernatant solution was removed and immediately analyzed with the E-tongue.

\subsection{Statistical analysis}

A two-way analysis of variance (two-way ANOVA) was performed to evaluate the effect of the plasticizers and additives used in the construction of the lipid membranes of the E-tongue, as well as the possible interaction between "plasticizer" and "additive". If
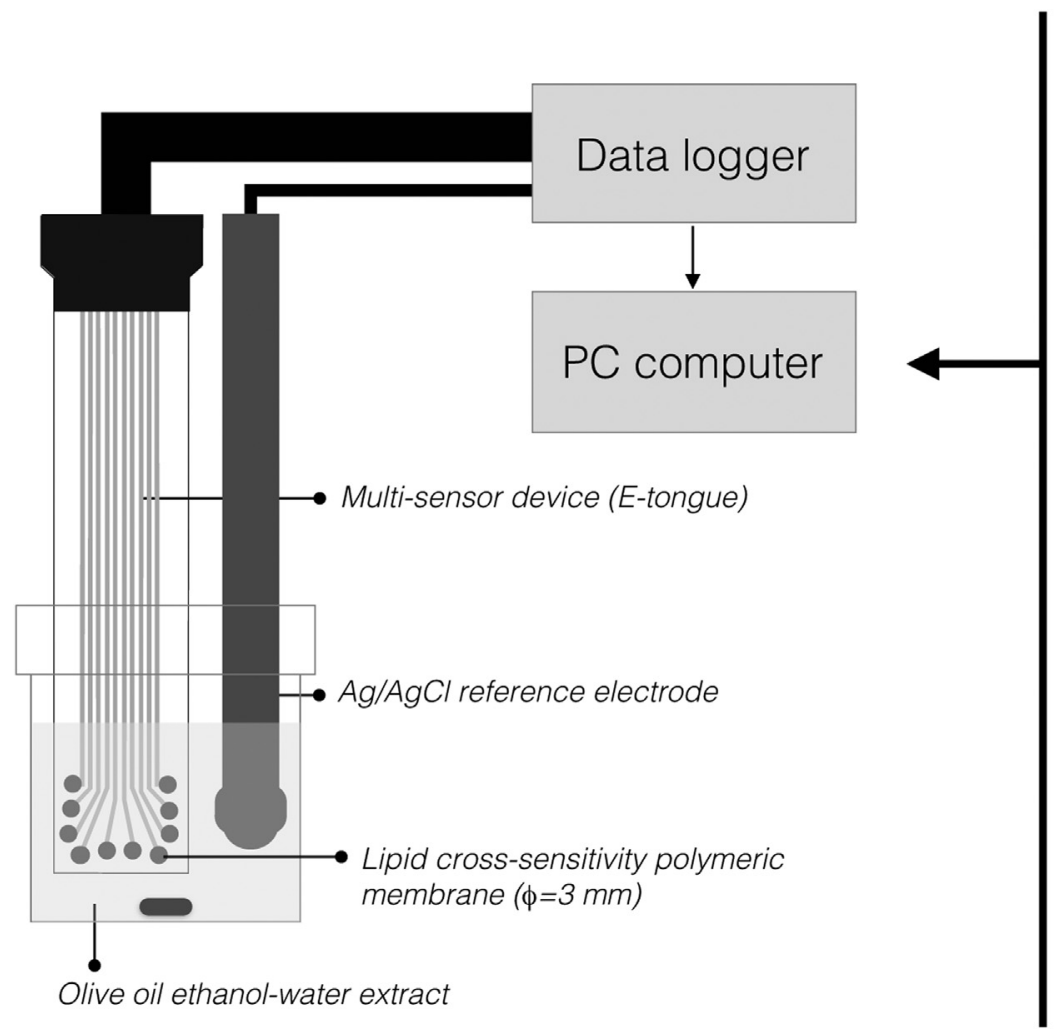

Signal measurement over time for a sample analysis:
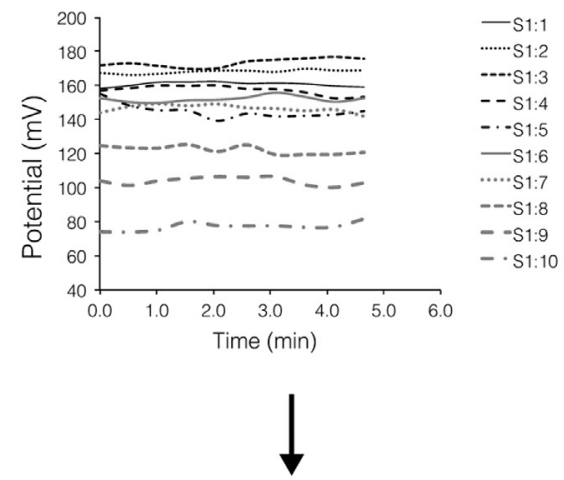

Olive oil samples' signal profiles:

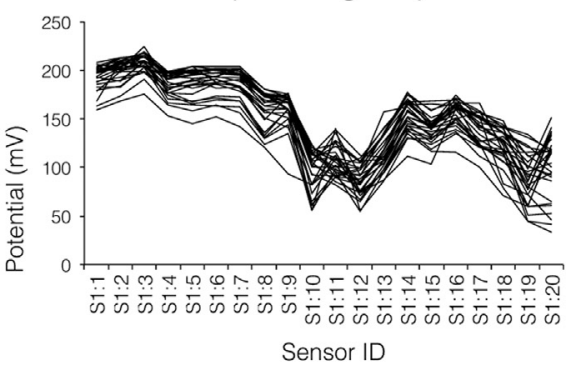

Fig. 1. Scheme on EVOO analysis: E-tongue system; exemplification of the recorded potentiometric signals; overall samples' signal profiles. 
no significant interaction effect was found, for each statistical significant factor, means were compared using the Tukey's multiple comparison test. Linear discriminant analysis (LDA) was also used as a supervised pattern recognition method to infer about the capability of the E-tongue to correctly classify EVOO according to the intensity sensory perception, as intense, medium and/or light olive oils. The best subsets of $K$ independent predictors among the 40 E-tongue potentiometric signals recorded were chosen using a meta-heuristic simulated annealing (SA) variable selection algorithm [35-37]. The SA algorithm selects the optimal conditions based on the assumptions of the annealing physic process using an iterative procedure. The algorithm searches for a global minimum that optimizes a system with $k(\subseteq K)$ variables. In each iteration, the solutions of the current and the new subsets of $k$ variables are compared using the tau 2 quality criterion, which is a measure of the goodness of fitting. A new solution is randomly selected in the neighborhood of the current solution, being selected if it gave a better result than the initial one. In general, 10,000 attempts are used to select the best subset of variables (best model), starting the process of selecting the best subsets of variables on each trial, thus ensuring a greater confidence in finding a true optimal solution. In the present study, for each sub-set of sensors under evaluation (possible combinations of 2-39 sensors), the set of sensors chosen was the one that resulted in the maximum value of tau2 [35]. To evaluate the LDA classification model, first a leaveone-out cross-validation (LOO-CV) procedure was applied. This process may lead to over-optimistic results although, it has proven to be an adequate procedure when the number of samples is low $[21,38]$. To minimize this risk, a K-fold cross-validation strategy was also applied to the sub-sets of sensors selected by the SA algorithm. For this purpose, data was divided into $\mathrm{K}$ subsets and $\mathrm{K}$ models were fitted, each time considering $\mathrm{K}-1$ subsets, as the training set, leaving out one of the subsets for the internal validation, to compute the predictive error for the obtained model [39]. The number of K-folds was set equal to 4, enabling the formation of internal validation subsets (for each sensory group) with $25 \%$ of initial data allowing bias reduction. Also, a repeated K-fold cross-validation procedure (with 10 repetitions) was implemented in this work to reduce the uncertainty of the estimates. To normalize the weight of each variable in the final linear classification model, variable scaling and centering procedures were evaluated. Finally, linear Pearson correlation coefficient ( $R$-Pearson) was applied to evaluate the existence of bivariate correlations between the space distribution of the sensory intensity groups and the total phenolic content of each group considered. All statistical analysis were performed using the Subselect [35] and MASS [40] packages of the open source statistical program $\mathrm{R}$ (version 2.15.1) at a significance level of $5 \%$.

\section{Results and discussion}

\subsection{EVOO grouping based on the intensity range of sensory positive attributes}

Each monovarietal EVOO sample was evaluated by 4 trained sensory panelists following the COI regulations [1,2]. In total, 14 organoleptic descriptors including 5 olfactory sensations, 7 gustatory-retronasal sensations and 2 final olfactory-gustatory sensations were assessed. Based on the intensity levels of 4 positive sensory attributes (olfactory olive fruitiness; gustatory-retronasal olive fruitiness, bitterness and pungency) assessed by the panelists, monovarietal EVOO samples of each production year (2012 or 2013) were classified as: IIII (if all four positive attributes were classified as intense), IIMI (intense olfactory and gustatory olive fruitiness; medium bitterness and intense pungency), IIMM (intense olfactory and gustatory-retronasal olive fruitiness; medium bitterness and pungency), IILL (intense olfactory and gustatory olive fruitiness; light bitterness and pungency). Details on the type of single-cultivar classified according to this commercial grade are given in Table 1 . Olive oils were grouped based on the overall intensity perception of all 4 positive attributes. By this procedure, possible synergetic interactions between the different positive sensory attributes and their effects in the overall human sensory perception could be considered simultaneously. All olive oil samples were classified as intense regarding both olfactory and gustatory-retronasal fruitiness, and ranged from intense to light for bitterness and pungency sensations (Table 1). Also, for EVOO from $c v$. Arbequina it was possible to collect samples in each crop year with different bitterness and/or pungency levels. In addition, bitterness or pungency intensities of monovarietal olive oils from cvs. Arbosana and Arroniz, perceived by the panelists, varied with the crop year.

\subsection{Total phenolic contents of EVOO}

Total phenolic contents of the 88 monovarietal EVOO studied (2012 and 2103 crop years) were quantified experimentally and the average concentrations and respective standard deviations (expressed as mg of caffeic acid equivalents per $\mathrm{kg}$ of olive oil, $\mathrm{mg}$ $\mathrm{CAE} / \mathrm{kg}$ ) are given in Table 3, for each intensity sensory group (IIII, IIMI, IIMM and/or IILL as proposed in Section 3.1) and production year. The number of samples and type of monovarietal EVOO included in each group are also reported. Olive oils were grouped according to the human assessment of the intensity perception of 4 sensory positive attributes (olfactory olive fruitiness, gustatoryretronasal olive fruitiness, bitterness and pungency sensations) as intense (I), medium (M) or light (L) [1,2].

A high variability was found in the total phenolic contents of olive oils (high standard deviations corresponding to variation coefficients usually greater than $10 \%$ ) classified as belonging to the same sensory intensity perception groups (IIII, IIMI or IIMM), with the exception of the IILL (olive oils with the lowest sensory intensity perception) (Table 3 ). Indeed, although a correlation is expected between total phenols contents and the intensity perception of sensory attributes (increasing phenols amounts would correspond to greater bitterness, pungency or astringency sensations), it has been reported that, depending on the molecular size, different sensory sensations may be enhanced due to the differentiated activation of human bitter taste receptors, tending larger molecules to be more astringent [41]. So, olive oils with similar average phenolic contents may develop different sensory perceptions, depending on the type and size of the phenols molecules present. Also, the variability found within each sensory intensity group could be tentatively attributed to the different type of monovarietal olive oils included in each group (ranging from 2 to 5 , except for IILL group that only contains samples from $c v$. Manzanilla), which have specific sensory characteristics but also different physico-chemical compositions. Nevertheless, an overall analysis indicate that an expected qualitative tendency can be found, showing that greater bitterness and pungency intensities would correspond to greater total phenols concentrations.

\subsection{E-tongue signals analysis}

\subsubsection{E-tongue response towards bitter standard solutions.}

The 40 potentiometric E-tongue signals were recorded for the ethanol-water solution (80:20, v/v) and after the addition of preestablished volumes of quinine monohydrochloride dihydrate standard solution $(0.302 \mathrm{~g} / \mathrm{L})$ (final quinine monohydrochloride: $0.00102-0.101 \mathrm{~g} / \mathrm{L}$ ). All the E-tongue polymeric membranes showed an increase of the potential response with increasing 
Table 3

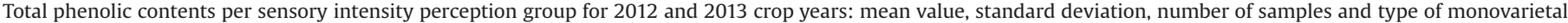
EVOO.

\begin{tabular}{|c|c|c|c|c|}
\hline Olive oil production year & Intensity sensory perception group & No. of samples & Single-cultivar EVOO & Total phenolic content $\bar{X}_{ \pm} s d(\mathrm{mg} \mathrm{CAE} / \mathrm{kg})$ \\
\hline \multirow[t]{4}{*}{2012} & IIII & 10 & $\begin{array}{l}\text { cv. Arbequina } \\
\text { cv. Arbosana } \\
\text { cv. Hojiblanca }\end{array}$ & $168 \pm 33$ \\
\hline & IIMI & 19 & $\begin{array}{l}\text { cv. Arbequina } \\
\text { cv. Arroniz } \\
\text { cv. Cornicabra } \\
\text { cv. Frantoio } \\
\text { cv. Picual }\end{array}$ & $163 \pm 25$ \\
\hline & IIMM & 11 & $\begin{array}{l}\text { cv. Arbequina } \\
\text { cv. Redondilla }\end{array}$ & $141 \pm 15$ \\
\hline & IILL & 4 & cv. Manzanilla & $106 \pm 2$ \\
\hline \multirow[t]{3}{*}{2013} & IIII & 8 & $\begin{array}{l}\text { cv. Hojiblanca } \\
\text { cv. Royuela }\end{array}$ & $246 \pm 72$ \\
\hline & IIMI & 20 & $\begin{array}{l}\text { cv. Arbequina } \\
\text { cv. Arbosana } \\
\text { cv. Frantoio } \\
\text { cv. Picual } \\
\text { cv. Zorzal }\end{array}$ & $200 \pm 22$ \\
\hline & IIMM & 16 & $\begin{array}{l}\text { cv. Arbequina } \\
\text { cv. Cornicabra } \\
\text { cv. Redondilla }\end{array}$ & $177 \pm 45$ \\
\hline
\end{tabular}
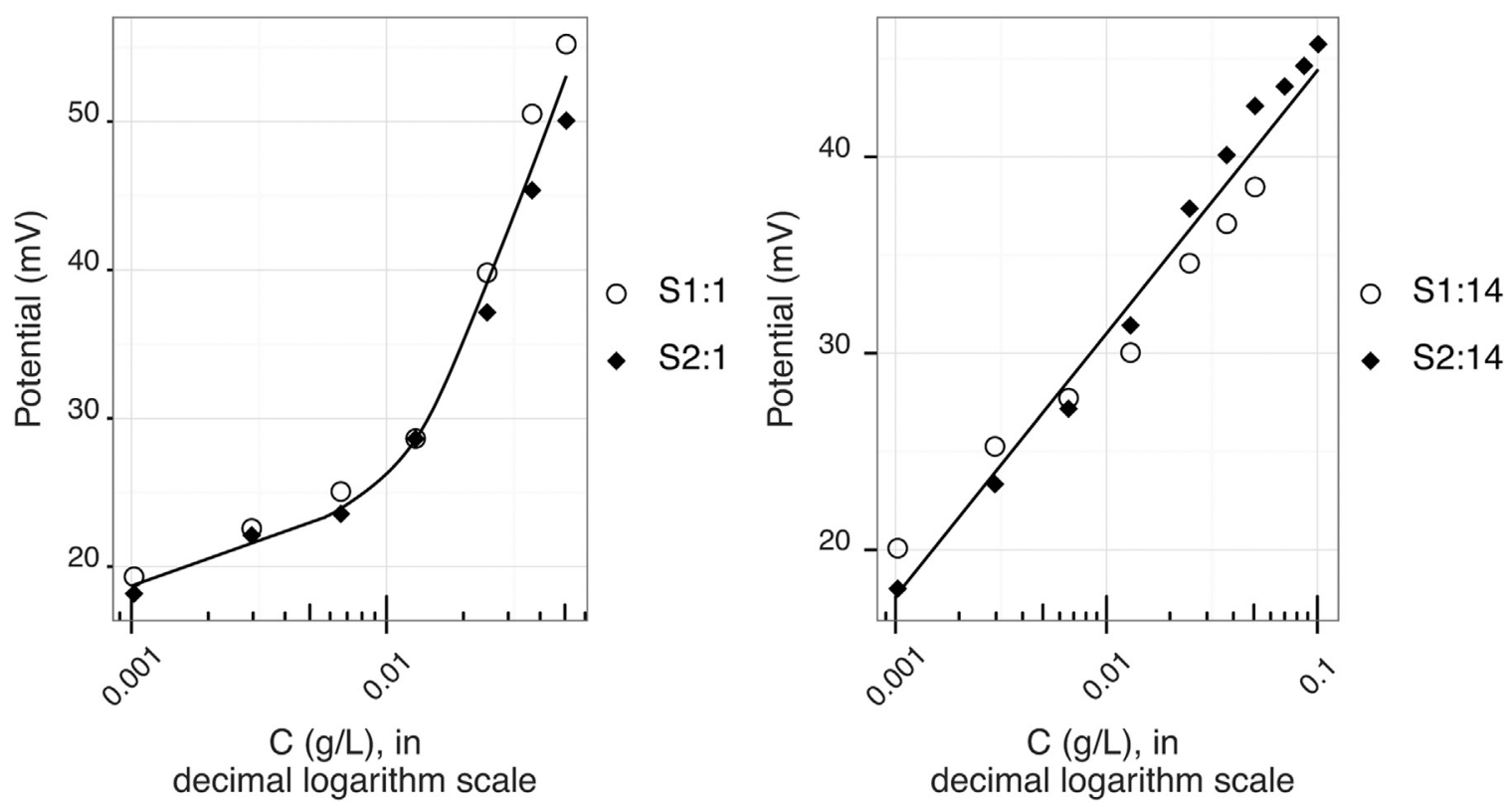

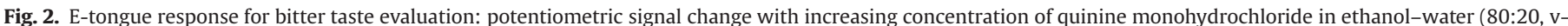

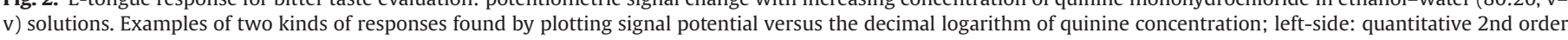

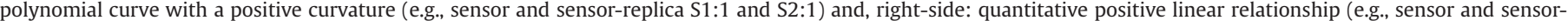
replica $\mathrm{S} 1: 14$ and $\mathrm{S} 2: 14)$.

quinine monohydrochloride concentrations, (i.e., a decrease of potential was not detected with the increase of chloride concentration). So, it could be inferred that the recorded signals were due mainly to the presence of quinine and not to any anionic species in solution, like chloride ion. In general, the potentiometric signals of the 40 sensors showed a potential signal increase of $16 \pm 6 \mathrm{mV}$ after the first addition (compared with the signal recorded for the blank solution: ethanol-water), demonstrating that, in general, all sensors and replicas respond to the presence of small amounts of quinine monohydrochloride. For the quinine concentration dynamic range studied, two types of quantitative responses towards increasing concentrations of quinine were observed. When the potential difference $(\mathrm{mV})$ was plotted against the decimal logarithm of the quinine concentration (in $\mathrm{mol} / \mathrm{L}, \mathrm{M}$ ), a quantitative positive linear relationship $\left(0.9676 \leq R^{2}\right.$-Pearson $\leq 0.9972$ ) or a 2 nd order polynomial curve with a concave curvature $\left(0.9738 \leq R^{2}\right.$-Pearson $\left.\leq 0.9980\right)$ were observed. Fig. 2 shows these two behaviors for the polymeric membranes 1 and 14 , for the 2 sensor arrays. The linear behavior was found, in both sensor arrays (sensor and sensor-replica), for 7 polymeric membranes (i.e, $8,13,14,15,16,17$ and 18) and the curvilinear behavior, for the other 13 polymeric membranes. In Table 2 , for each pair of polymeric membranes it is also reported the mean sensitivities (slope values, $\mathrm{mV} /$ decade), the standard deviations ( $\mathrm{mV} /$ decade) and the 


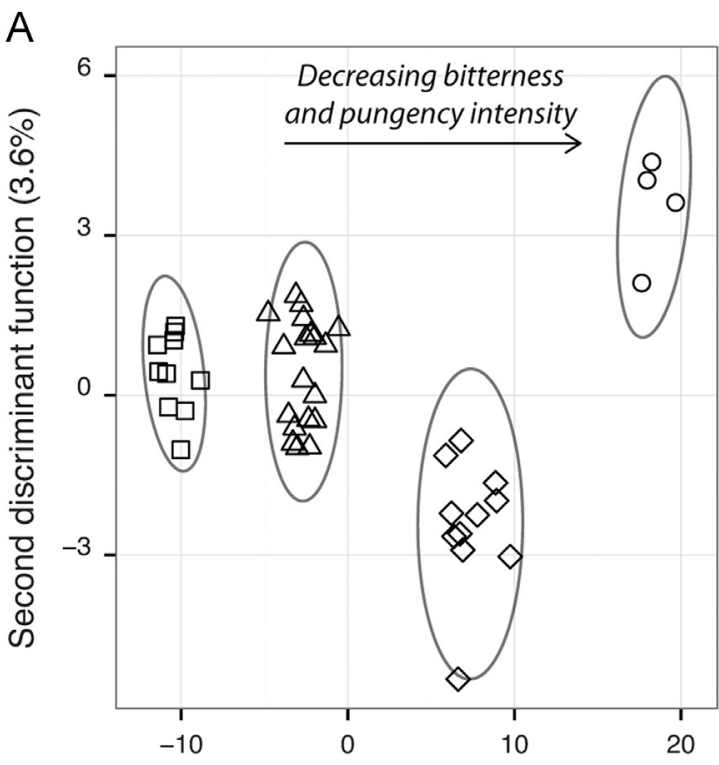

First discriminant function (94.4\%)

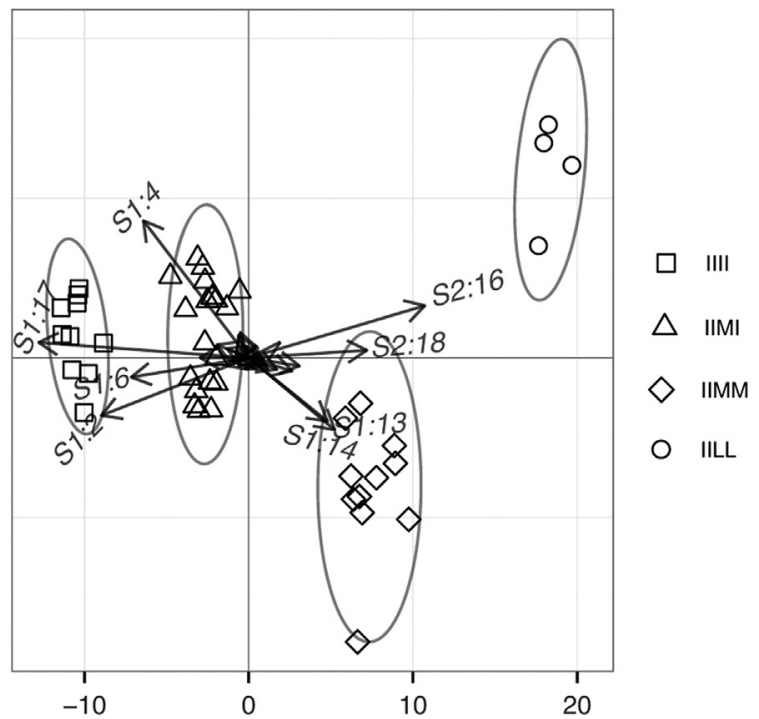

First discriminant function (94.4\%)

B

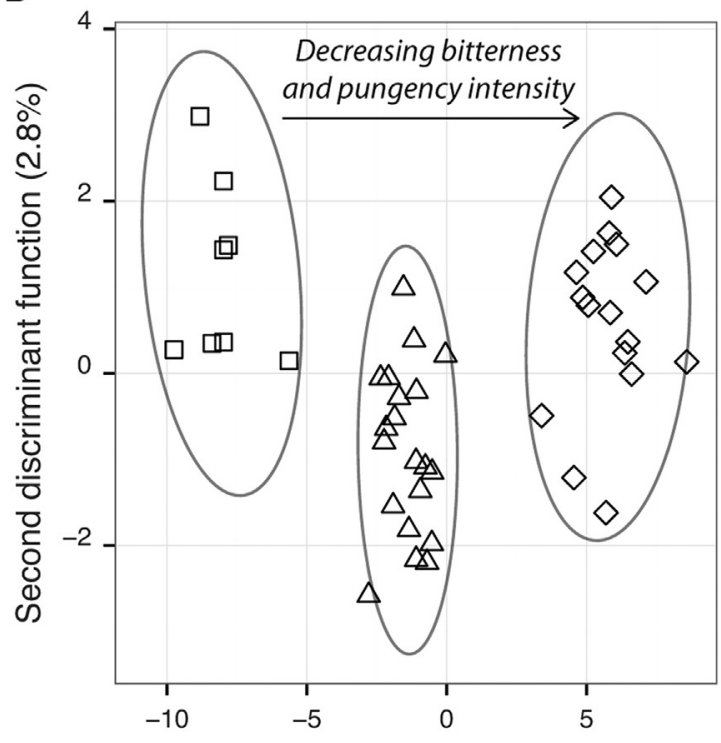

First discriminant function (97.2\%)

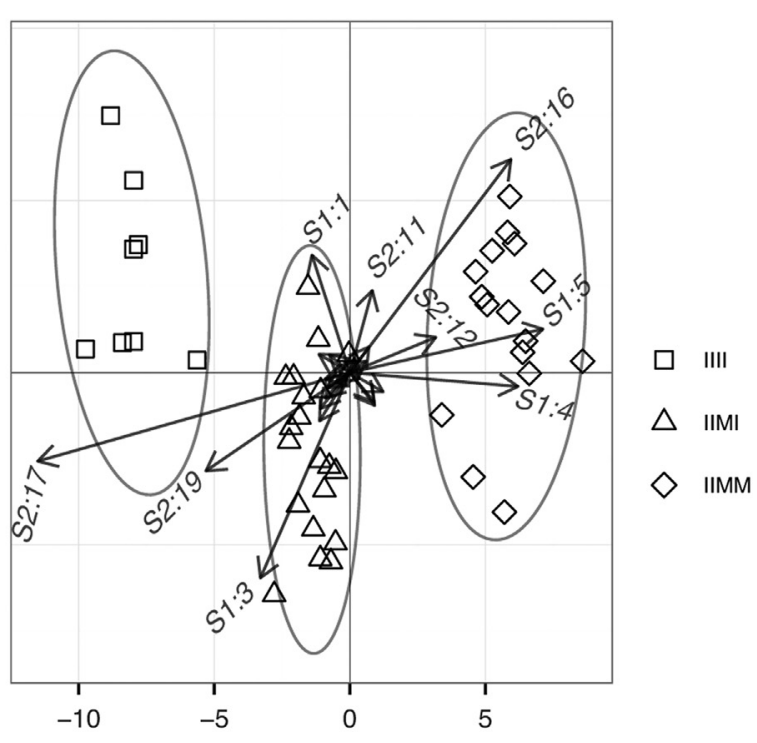

First discriminant function (97.2\%)

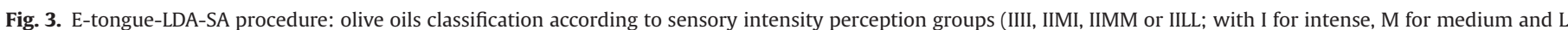

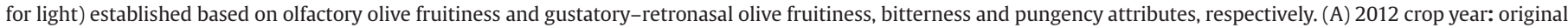

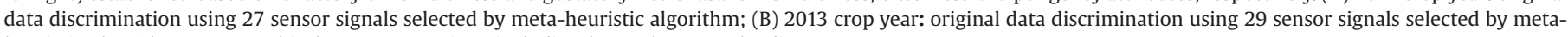
heuristic algorithm. Two graphical outputs are given including (or not) sensors loading arrows.

respective linear dynamic concentration range ( $\mathrm{M}$ and $\mathrm{g} / \mathrm{L}$ ). These latter were calculated from the slope values of different calibrations carried out for each pair of sensor and respective sensorreplica of the E-tongue device. The results indicate that all plasticizer/additive pairs used respond to increasing quinine monohydrochloride levels and the respective linear dynamic concentration ranges include the quinine concentrations usually used during sensory panelists training (i.e., 0.025 to $0.050 \mathrm{~g} / \mathrm{L}$ ) [33,34]. It can also be inferred that some plasticizers enhance the E-tongue sensitivity towards quinine monohydrochloride (i.e, bitter sensation), namely bis(1-butylpentyl) adipate and dibutyl sebacate, independently of the additive compound used. Indeed, a two-way ANOVA showed that there was no significant interaction effect ("plasticizer $\times$ additive": $P$-value $=0.3164$ ). No statistical significant effect was also found due to the type of additive used on the lipid membrane $(P$-value $=0.2604)$. On the other hand, the type of plasticizer had a statistical significant effect on the sensor sensitivity $(P$-value $=0.0001)$, showing that bis(1-butylpentyl) adipate and dibutyl sebacate had similar sensitivities $(25 \pm 6$ and $24 \pm 5 \mathrm{mV} /$ decade; $P$-value $=0.9798$, Tukey's test) towards quinine monohydrochloride and significantly greater $(P$-value $\leq 0.030$, Tukey's test) than the sensitivities observed for the other three plasticizers ( $16 \pm 5,14 \pm 2$ and $18 \pm 3 \mathrm{mV} /$ decade for 2-nitrophenyl-octyl ether, tris(2-ethylhexyl) phosphate and dioctyl phenylphosphonate, respectively; $P$-value $\geq 0.3961$, Tukey's test). Nevertheless, it should be noticed that, the plasticizers with lower sensitivities had, in general, a broader linear dynamic concentration range (including the lowest and highest quinine monohydrochloride levels), which could be quite important for differentiate light and intense EVOOs (Table 2). 


\subsubsection{E-tongue analysis of EVOO samples}

In total, 88 potentiometric assays were carried out, corresponding to the 88 samples of the 11 monovarietal EVOO collected. Since the E-tongue had non-specific cross-sensitivity sensors, the signals profiles correspond to an overall fingerprint of the matrix under analysis, rather than to a specific compound. Each analysis provided 40 signals (20 sensors and the respective replicas), which signals varied from $-0.04 \mathrm{~V}$ to $+0.25 \mathrm{~V}$. Since the voltage signals, recorded during the analysis of the EVOO ethanolwater extracts $(80: 20 \mathrm{v} / \mathrm{v})$ were of similar magnitude for all sensors, no data scaling was performed. The differences found for the signals recorded by two sensor replicas may be attributed to slight variations of the membrane composition and physical properties (transparency and porosity) that may occur due to the drop-bydrop technique applied, which may lead to the formation of inhomogeneous membranes [21].

Since, sensory attributes of EVOO may be quite influenced by the edaphoclimatic conditions, olive oils were grouped by crop year (2012 and 2013). For each crop year, EVOO were classified according to the intensity of four positive organoleptic attributes, as previously described. So, olive oils samples were split into different overall intensity sensory perception groups namely, 4 groups (IIII, IIMI, IIIMM and IILL) and 3 groups (IIII, IIMI and IIMM), for 2012 and 2013 crop years, respectively.

Regarding the 44 single-cultivar EVOO samples from 2012 crop year, the E-tongue potentiometric signals were subjected to a supervised LDA coupled with a SA variable selection algorithm, aiming minimizing the number of independent variables (sensors and sensors replicas) to be included in the final discrimination model, to exclude non-informative or high collinear variables. The final model, with 27 sensors (in sensor array 1: S1:2 to S1:4, S1:6, $\mathrm{S} 1: 9, \mathrm{~S} 1: 10, \mathrm{~S} 1: 12, \mathrm{~S} 1: 13, \mathrm{~S} 1: 15$ to $\mathrm{S} 1: 18$; in sensor array $2: \mathrm{S} 2: 1$ to S2:6, S2:8, S2:9, S2:12 to S2:14, S2:16 to S2:18, S2:20) had 3 significant discriminant functions that explained $100 \%$ of the original data variability $(94.4 \%, 3.6 \%$ and $2.0 \%$ ). The selected sensors and sensor replicas included all the plasticizer-additives combinations used, being bis(1-butylpentyl) adipate plasticizer the most common. Concerning the additives, all the 5 compounds used were similarly present in the sensors-sensors replicas included in the final discriminant model. The established linear discriminant model enabled $100 \%$ of correct classification for the original grouped data (Fig. 3A) and 91\% of correct classifications for the LOO-CV procedure (one sample of IIII was misclassified as belonging to IIMI group; one sample from IIMI misclassified as IIII and two samples as IIMM), i.e., the model showed a specificity of $100 \%$ for EVOO samples belonging to IILL and IIMM groups.

Similarly, 44 monovarietal EVOO samples of 2013 crop year were grouped into 3 intensity sensorial level groups based on the sensory panel rating of the 4 positive organoleptic sensations as IIII, IIMI and IIMM. In this case 2 significant discriminant functions explained $100 \%$ of the data variability $(97.2 \%$ and $2.8 \%$ ) and the final model was based on the signal potentiometric profiles of 23 sensors and sensor-replicas (sensors: S1:1, S1:3 to S1:5, S1:10 to $\mathrm{S} 1: 13, \mathrm{~S} 1: 15$ to S1:17, S1:20; sensor-replicas: S2:2, S2:4 to S2:7, $\mathrm{S} 2: 9, \mathrm{~S} 2: 11, \mathrm{~S} 2: 12, \mathrm{~S} 2: 16, \mathrm{~S} 2: 17, \mathrm{~S} 2: 19)$. The linear discriminant model established allowed $100 \%$ of correct classifications of the original grouped data (Fig. 3B) and 91\% for the LOO-CV procedure. Indeed, one sample belonging to IIII group was misclassified as belonging to the IIMI group; one sample from IIMI group misclassified as IIMM group; and finally, two samples of IIMM group misclassified as IIMI group.

Overall, for the samples evaluated, it is interesting to observe that, independently of the year under analysis, the spatial location of the EVOO sensory intensity groups (sensory intensity group centroids position: IIII $<$ IIMI $<$ IIMM $<$ IILL) in the LDA plots, may be inversely correlated with the increasing scores of the 1 st linear discriminant function (lower olive oil bitterness and pungency perceptions would correspond to greater function scores). So, hypothetically, the 1st linear function could be used for a preliminary tool of olive oils intensity assessment, namely for bitterness and pungency attributes. Moreover, the same order found for the sensory intensity olive oils group centroids of the 1 st discriminant function was negatively correlated $\left(R^{2}\right.$-Pearson values equal to 0.9465 and 0.9560 for 2012 and 2013, respectively) with the total phenols average contents of the olive oil samples included in each group, strengthen the expected behavior that, increased phenols concentrations corresponded to greater bitterness and pungency intensities. Also, these results strengthen the idea that the potentiometric E-tongue mimics olive oil taste human sensations, namely bitterness and pungency levels. This potential was expected since it had been described that lipid polymeric membranes could recognize and assess standard solutions of basic taste compounds like acid, bitter, salty, sweet and umami [31].

To further test the robustness of the LDA model predictive performance to classify EVOO samples according to their intensity sensory perception, a repeated K-fold cross-validation strategy (4 folds $\times 10$ repetitions) was applied. In total, data were randomly split 40 times, into two data sub-sets, one for training purposes (containing $75 \%$ of the data) and the other for internal-validation (containing 25\% of the data). For olive oils from 2012, the best predictive classification results were obtained using a LDA model based on 25 sensors (lower than the number of sensors used for LOO-CV), resulting in an average correct classification of $80.2 \%$ of the samples used for internal-validation with an overall average specificity of $80.9 \%$. Similarly, for EVOO samples from 2013, the best LDA model was established with 22 sensors (also lower than the number of sensors used for LOO-CV) showing a mean sensitivity of $82.3 \%$ and an overall mean specificity of $84.4 \%$. In both cases, depending on the internal-validation fold randomly established the sensitivities and specificities of the LDA models varied from $64 \%$ to $100 \%$ and from $59 \%$ to $100 \%$, respectively. The mean correct classification percentages obtained are quite satisfactory and show that the E-tongue coupled with the LDA-SA procedure has suitable robustness, mainly since a broad type of single-cultivar EVOO are evaluated simultaneously and were from different olive oil producers. So, the E-tongue device could be used for a preliminary sensory evaluation of EVOO samples, and better performances could be foreseen depending on the data selected for training and internal-validation data sub-sets, namely ensuring that for training purposes suitable EVOO samples from the same single-cultivar could be used as representative standards of each intensity sensory perception group.

\section{Conclusion}

Nowadays, it is quite common to find olive oils labeled according to the sensory intensity perceptions (as intense, medium or light). This classification is commercially interesting for producers and appreciated by consumers, namely when purchasing EVOO. However, it largely depends on the sensory panels' assessment of positive organoleptic attributes, which is not a simple task, requires time and the existence of an available trained panel. In this work it was demonstrated, for the first time, the feasibility of applying a potentiometric E-tongue, containing lipid crosssensitivity polymeric membranes to discriminate monovarietal EVOO according to their overall sensory intensity classification (combinations of intense, medium and/or light of olfactory olive fruitiness and gustatory-retronasal olive fruitiness, bitterness and pungency attributes). The multi-sensor device, together with the appropriate chemometric tool (LDA-SA procedure) showed a satisfactory correct prediction capability of the overall intensity 
sensory perception of EVOO samples belonging to the internalvalidation data sub-sets. So, considering the satisfactory results, a future practical and useful application of the proposed procedure (E-tongue with LDA-SA) for olive oil sensory evaluation could be foreseen.

\section{Acknowledgment}

This study was supported by Fundação para a Ciência e a Tecnologia (FCT), Portugal and the European Community fund FEDER, under the Program PT2020 (Project UID/EQU/50020/2013); under the strategic funding of UID/BIO/04469/2013 unit; and by Project POCTEP through Project RED/AGROTEC - Experimentation network and transfer for development of agricultural and agro industrial sectors between Spain and Portugal.

\section{References}

[1] International Olive Council, Sensory Analysis of Olive Oil - Method for the Organoleptic Assessment of Virgin Olive Oil. COI/T.20/Doc. No 15/Rev. 〈http:// www.internationaloliveoil.org/ $\rangle, 2013,18$ pp. (accessed 06.11.13).

[2] International Olive Council, IOC Mario Solinas Quality Award - Rules of the International Competition for Extra Virgin Olive Oils. T.30/Doc. No. 17 http:// www.internationaloliveoil.org/>, 2014, 9 pp. (accessed 17.06.14).

[3] R. Garcia, N. Martins, M.J. Cabrita, Putative markers of adulteration of extra virgin olive oil with refined olive oil: prospects and limitations, Food Res. Int. 54 (2013) 2039-2044.

[4] J.C. Moore, J. Spink, M. Lipp, Development and application of a database of food ingredient fraud and economically motivated adulteration from 1980 to 2010, J. Food Sci. 77 (2012) R118-R126.

[5] C.A. Nunes, Vibrational spectroscopy and chemometrics to assess authenticity, adulteration and intrinsic quality parameters of edible oils and fats, Food Res. Int. 60 (2013) 255-261.

[6] C. Pizarro, S. Rodríguez-Tecedor, N. Pérez-del-Notario, I. Esteban-Díez, J. M. González-Sáiz, Classification of Spanish extra virgin olive oils by data fusion of visible spectroscopic fingerprints and chemical descriptors, Food Chem. 138 (2013) 915-922.

[7] N. Sinelli, L. Cerretani, V. Di Egidio, A. Bendini, E. Casiraghi, Application of near (NIR) infrared and mid (MIR) infrared spectroscopy as a rapid tool to classify extra virgin olive oil on the basis of fruity attribute intensity, Food Res. Int. 43 (2010) 369-375.

[8] A. Bakhouche, J. Lozano-Sánchez, R. Beltrán-Debón, J. Joven, A. Segura-Carretero, A. Fernández-Gutiérrez, Phenolic characterization and geographical classification of commercial Arbequina extra-virgin olive oils produced in southern Catalonia, Food Res. Int. 50 (2013) 401-408.

[9] C. Bazakos, A.O. Dulger, A.T. Uncu, S. Spaniolas, T. Spano, P. Kalaitzis., A SNPbased PCR-RFLP capillary electrophoresis analysis for the identification of the varietal origin of olive oils, Food Chem. 134 (2012) 2411-2418.

[10] P. Dais, E. Hatzakis, Quality assessment and authentication of virgin olive oil by NMR spectroscopy: a critical review, Anal. Chim. Acta 765 (2013) 1-27.

[11] R. Garrido-Delgado, F. Mercader-Trejo, S. Sielemann, W. de Bruyn, L. Arce, M. Valcárcel, Direct classification of olive oils by using two types of ion mobility spectrometers, Anal. Chim. Acta 696 (2011) 108-115.

[12] I. Karabagias, Ch Michos, A. Badeka, S. Kontakos, I. Stratis, M.G. Kontominas, Classification of Western Greek virgin olive oils according to geographical origin based on chromatographic, spectroscopic, conventional and chemometric analyses, Food Res. Int. 54 (2013) 1950-1958.

[13] F. Longobardi, A. Ventrella, C. Napoli, E. Humpfer, B. Schütz, H. Schäfer, M. G. Kontominas, A. Sacco, Classification of olive oils according to geographica origin by using ${ }^{1} \mathrm{H}$ NMR fingerprinting combined with multivariate analysis, Food Chem. 130 (2012) 177-183.

[14] C. Montealegre, M.L.M. Alegre, C. García-Ruiz., Traceability markers to the botanical origin in olive oils, J. Agric. Food Chem. 58 (2010) 28-38.

[15] C. Romero, M. Brenes, Analysis of total contents of hydroxytyrosol and tyrosol in olive oils, J. Agric. Food Chem. 60 (2012) 9017-9022.

[16] C. Ruiz-Samblás, A. Tres, A. Koot, S.M. van Ruth, A. González-Casado, L. Cuadros-Rodríguez, Proton transfer reaction-mass spectrometry volatile organic compound fingerprint for monovarietal extra virgin olive oil identification, Food Chem. 134 (2012) 589-596.

[17] C. Apetrei, I.M. Apetrei, S. Villanueva, J.A. de Saja, F. Gutierrez-Rosales, M. L. Rodriguez-Mendez, Combination of an e-nose, an e-tongue and an e-eye for the characterisation of olive oils with different degree of bitterness, Anal. Chim. Acta 663 (2010) 91-97.

[18] I.M. Apetrei, C. Apetrei, Voltammetric e-tongue for the quantification of total polyphenol content in olive oils, Food Res. Int. 54 (2013) 2075-2082.

[19] M.S. Cosio, D. Ballabio, S. Benedetti, C. Gigliotti, Geographical origin and authentication of extra virgin olive oils by an electronic nose in combination with artificial neural networks, Anal. Chim. Acta 567 (2006) 202-210.

[20] M.S. Cosio, D. Ballabio, S. Benedetti, C. Gigliotti, Evaluation of different storage conditions of extra virgin olive oils with an innovative recognition tool built by means of electronic nose and electronic tongue, Food Chem. 101 (2007) 485-491.

[21] L.G. Dias, A. Fernandes, A.C.A. Veloso, A.A.S.C. Machado, J.A. Pereira, A.M. Peres, Single-cultivar extra virgin olive oil classification using a potentiometric electronic tongue, Food Chem. 160 (2014) 321-329.

[22] M.E. Escuderos, S. Sánchez, A. Jiménez, Virgin olive oil sensory evaluation by an artificial olfactory system, based on Quartz Crystal Microbalance (QCM) sensors, Sens. Actuators B 147 (2010) 159-164.

[23] M.E. Escuderos, S. Sánchez, A. Jiménez., Quartz Crystal Microbalance (QCM) sensor arrays selection for olive oil sensory evaluation, Food Chem. 124 (2011) 857-862.

[24] Z. Haddi, H. Alami, N. El Bari, M. Tounsi, H. Barhoumi, A. Maaref, N. JaffrezicRenault, B. Bouchikhi, Electronic nose and tongue combination for improved classification of Moroccan virgin olive oil profiles, Food Res. Int. 54 (2013) $1488-1498$

[25] Z. Haddi, A. Amari, A.O. Ali, N. El Bari, H. Barhoumi, A. Maaref, N. JaffrezicRenault, B. Bouchikhi, Discrimination and identification of geographical origin virgin olive oil by an e-nose based on MOS sensors and pattern recognition techniques, Procedia Eng. 25 (2011) 1137-1140.

[26] M.J. Lerma-García, E.F. Simó-Alfonso, A. Bendini, L. Cerretan, Metal oxide semiconductor sensors for monitoring of oxidative status evolution and sensory analysis of virgin olive oils with different phenolic content, Food Chem. 117 (2009) 608-614.

[27] P. Oliveri, M.A. Baldo, S. Daniele, M. Forina, Development of a voltammetric electronic tongue for discrimination of edible oils, Anal. Bioanal. Chem. 395 (2009) 1135-1143.

[28] A.M. Peres, A.C.A. Veloso, J.A. Pereira, L.G. Dias, Electrochemical multi-sensors device coupled with heuristic or meta-heuristic selection algorithms for single-cultivar olive oil classification, Procedia Eng. 87 (2014) 192-195.

[29] I. Lauri, B. Pagano, A. Malmendal, R. Sacchi, E. Novellino, A. Randazzo, Application of "magnetic tongue" to the sensory evaluation of extra virgin olive oil, Food Chem. 140 (2013) 692-699.

[30] C. Capannesi, I. Palchetti, M. Mascini, A. Parenti, Electrochemical sensor and biosensor for polyphenols detection in olive oils, Food Chem. 71 (2000) $553-562$.

[31] L.G. Dias, A.M. Peres, A.C.A. Veloso, F.S. Reis, M. Vilas Boas, A.A.S.C. Machado, An electronic tongue taste evaluation: identification goat milk adulterations with bovine milk, Sens. Actuators B 136 (2009) 209-217.

[32] Y. Kobayashi, M. Habara, H. Ikezazki, R. Chen, Y. Naito, K. Toko, Advanced taste sensors based on artificial lipids with global selectivity to basic taste qualities and high correlation to sensory scores, Sens 10 (2010) 3411-3443.

[33] European Commission Regulation No. 796, OJEU, L.128, May 6th, 2002, pp. 828.

[34] F. Favati, N. Condelli, F. Galgano, M.C. Caruso., Extra virgin olive oil bitterness evaluation by sensory and chemical analyses, Food Chem. 139 (2013) 949-954.

[35] J. Cadima, J.O. Cerdeira, M. Minhoto, Computational aspects of algorithms for variable selection in the context of principal components, Comput. Stat. Data Anal. 47 (2004) 225-236.

[36] S. Kirkpatrick, C.D. Gelatt, M.P. Vecchi, Optimization by simulated annealing, Science 220 (1983) 671-680.

[37] D. Bertsimas, J. Tsitsiklis, Simulated annealing, Stat. Sci. 8 (1993) 10-15.

[38] J.M. Gutiérrez, Z. Haddi, A. Amari, B. Bouchikhi, A. Mimendia, X. Cetó, M. del Valle, Hybrid electronic tongue based on multisensor data fusion for discrimination of beers, Sens. Actuators B 177 (2013) 989-996.

[39] M. Kuhn, K. Johnson, Applied Predictive Modeling, Springer Science+Business Media, New York, USA, 2013.

[40] W.N. Venables, B.D. Ripley, Modern Applied Statistics With S (Statistics and Computing), 4th edition, Springer, New York, USA, 2002.

[41] S. Soares, S. Kohl, S. Thalmann, N. Mateus, W. Meyerhof, V. De Freitas, Different phenolic compounds activate distinct human bitter taste receptors, J. Agric. Food Chem. 61 (2013) 1525-1533. 